\title{
Influence of Ethnicities and Skin Color Variations in Different Populations: A Review
}

\author{
Piyu Parth Naik ${ }^{a}$ Syed Nadir Farrukh ${ }^{b}$ \\ aDepartment of Dermatology, Saudi-German Hospital \& Clinic, Dubai, UAE; bepartment of Internal Medicine, \\ Adam-Vital Hospital, Dubai, UAE
}

\section{Keywords}

Skin color · Ethnicity · Genetic factors · Melanin

\begin{abstract}
Background: In the world scientific tradition, skin color is the primary physical characteristic used to divide humans into groups. Human skin has a wide range of tones and colors, which can be seen in a wide range of demographic populations. Many factors influence the color of people's skin, but the pigment melanin is by far the most important. Melanin is produced by cells called melanocytes in the skin and is the primary determinant of skin color in people with darker skin. Indeed, >150 genes have now been identified as having a direct or indirect effect on skin color. Vitamin D has recently been discovered to regulate cellular proliferation and differentiation in a variety of tissues, including the skin. The mechanisms through which the active vitamin D metabolite 1,25 dihydroxyvitamin D3 (or calcitriol) affects keratinocyte development are numerous and overlap with the mechanisms by which calcium influences keratinocyte differentiation. UItraviolet (UV) is the most major modifiable risk factor for skin cancer and many other environmental-influenced skin disorders when it is abundant in the environment. Although the UV component of sunlight is known to cause skin damage, few researches have looked at the impact of non-UV solar
\end{abstract}

radiation on skin physiology in terms of inflammation, and there is less information on the role of visible light in pigmentation. Summary: The quantity and quality of melanin are regulating by the expression of genes. The enzyme tyrosinase is primarily responsible for the genetic mechanism that controls human skin color. Genetics determines constitutive skin color, which is reinforced by facultative melanogenesis and tanning reactions. High quantities of melanin and melanogenic substances are typically accepted in darker skin to protect against UV radiation-induced molecular damage. Previous research has proposed that skin color variation is caused by a dynamic genetic mechanism, contributing to our understanding of how population demographic history and natural selection shape human genetic and phenotypic diversity. However, the most significant ethnic skin color difference is determined by melanin content. This current review aimed to assess the influence of skin color variations in skin structure and functions as well as difference in dermatological disease patterns. Also, this article reviewed several cases of skin color adaptation in different populations. Key Messages: Skin color impacts the composition and activity. Therefore, the contrast of dermatological ailments between distinct race-related categories is remarkable. Skin color adaptation is a challenging procedure. Refinement of skin color is an age-old craving of humans with ever-evolving drifts. karger@karger.com

www.karger.com/spp

Karger $\stackrel{2}{*}$

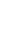

(C) 2021 S. Karger AG, Basel 


\section{Introduction}

One of the most striking examples of human phenotypic variability is skin color variation [1]. Melanin, a pigment produced by melanocytes at the base of the epidermis, is the most prominent pigment. Melanin has 2 forms, eumelanin (black-brown) and pheomelanin (yellow-reddish). The former is primarily collected in lightskinned people, while light-skinned persons are more likely to develop the latter [2,3]. Furthermore, the size and number of melanin particles vary by the organism and are even more significant in determining human skin color than the proportions of the 2 types of melanin [4]. Some skin-related factors, such as keratin, also influence skin color $[5,6]$. We know a lot about the genetic architecture of human skin color, but we do not know much about it, which can be related to climates, cultures, and continents. Historically, human skin color has been measured using subjective categories: "moderate brown, occasionally burns, tans easily." Quantitative approaches focused on reflectance spectrophotometry have recently been used to differentiate between reddening induced by inflammation and increased hemoglobin and darkening caused by enhanced melanin $[7,8]$. The organic polymer of melanin is made up of oxidative tyrosine derivatives in 2 types, including a cysteine-rich red-yellow form (pheomelanin) and a less soluble black-brown form (eumelanin). Chemical extraction is needed to distinguish between pigment types in biological samples, but it is worthwhile because pigment-type switching is one of the few things we learn about the most prevalent variations in human pigmentation $[9,10]$.

Skin color is significantly related to latitude and, more importantly, the ultraviolet (UV) radiation distribution in global populations. The skin of those who live near the equator is darker to shield themselves from UV rays, which can lower folic acid levels [11] and cause skin cancer $[12,13]$. Higher latitude populations have lighter skin due to selection to protect vitamin $\mathrm{D}$ photosynthesis, which is a UV-dependent process [14]. While UV was formerly thought to be a driving force in the evolution of human skin tones, the specific genetic mechanism of selection is still unknown. Nevertheless, it is critical for understanding the microevolution of adaptive traits and reconstructing human evolutionary history. It would be impossible to give a comprehensive account of human regional skin color adaptation as it would need not only the genes that have been described as being under selection but also the extent to which these genes may be able to account for combined impacts, gene interactions, and phenotypic variation and how they respond to external environments [15]. With these backgrounds, the current review is aimed to evaluate the influence of skin color variations in skin structure and functions. Also, this article reviewed several cases of skin color adaptation in different populations.

\section{Methodology}

A literature search was carried out on the following databases, including Google Scholar, MEDLINE, PubMed, Scopus, and Cochrane databases with the appropriate key terms. We were looking specifically for articles on the influence of ethnicities and skin color variations in different populations. The initial literature search revealed 8,667 articles, which is detailed in Figure 1. All the published articles were reports with a description of skin color variation, articles published in the English language, and all study designs were included in this review.

\section{Results and Discussion}

\section{Variations in Skin Coloration}

The difference in skin pigmentation between ethnic groups is the most prominent [16]. The amount of melanin in the skin, the amount of UV exposure, genetics, the quality of melanosomes, and pigments present in the skin all play a role in racial variation. The different colors present in human skin are caused by 4 chromophores: carotenoids, hemoglobin, melanin, and oxyhemoglobin. By absorbing unique light wavelengths and allowing red to be reflected, oxyhemoglobin and hemoglobin lead to the pinkish color of Caucasian skin. Melanin is responsible for the different brown shades seen in black and suntanned skin. Carotenoids cause yellow-orange pigmentation. A mixture of all the pigments causes other hues. Orthoquinones are produced during melanogenesis, and they have a high predisposition for interacting with protein and nucleic acids and covalently adhering to them.

As a consequence, melanogenesis is limited to specialized organelles known as melanosomes [17]. By the time the organelles are completely melanized and transported to keratinocytes as granules, the response of melanosomal proteins and intermediate quinines has resulted in a correct pattern of matrix deposition and inhibition of tyrosinase and other enzymes. Australian aborigines, African-blacks, and Americans have been found to have more melanosomes. Compared to other racial groups, these ethnic groups' melanosomes are also more scattered and larger individually. Melanosomes were present in Mon-
Naik/Farrukh 
Fig. 1. PRISMA flowchart.

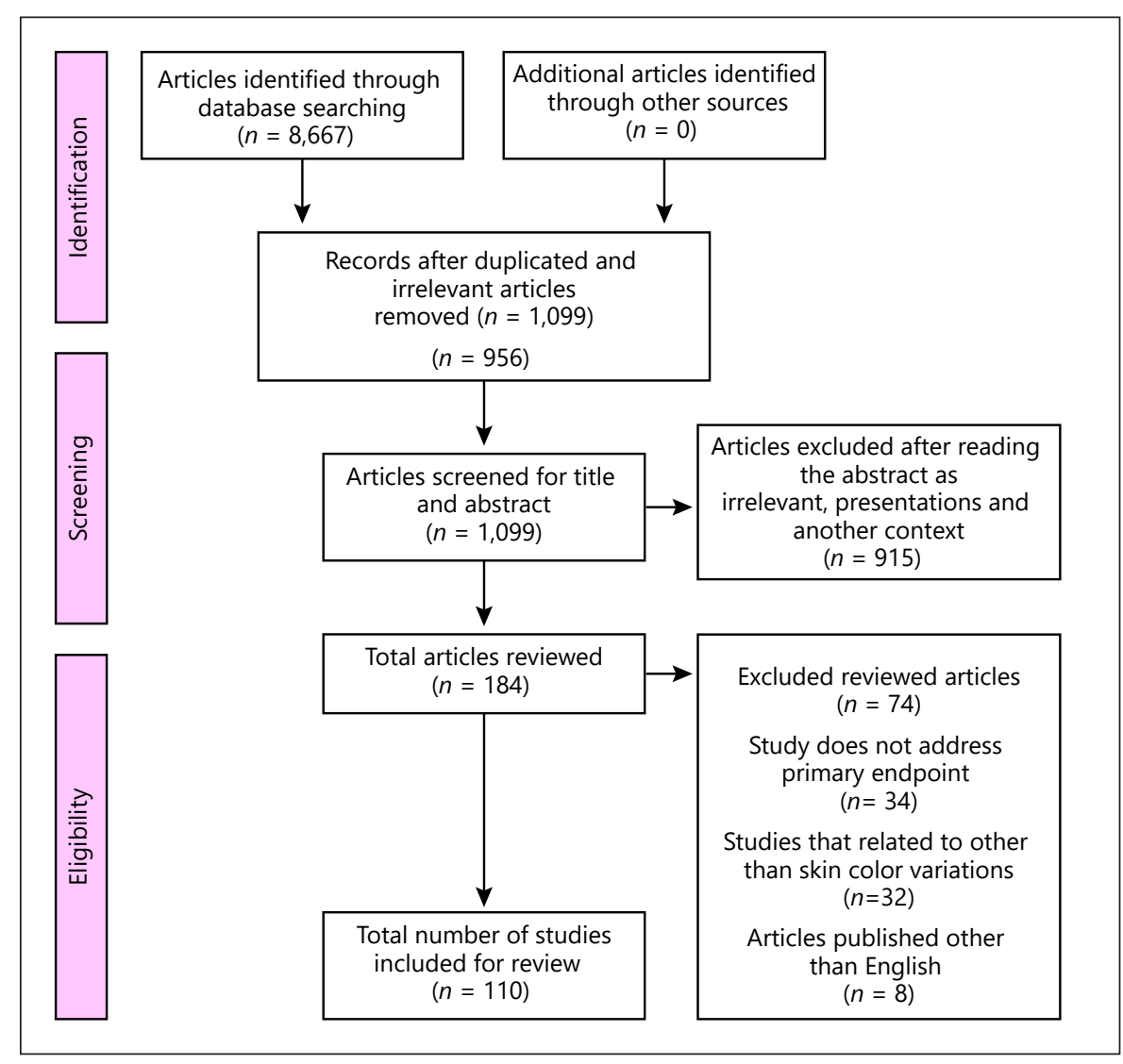

goloids, Chinese, Japanese, East Indians, and EuropeanAmerican Caucasians clustered together in complexes of 2 or more. Differences in skin pigmentation are caused by melanosome arrangement variations and the quantity of melanin present [16].

Melanogenesis, on the other hand, is a gradual process that happens following exposure to UV light. After a single UV dose, the quantity of melanin in black skin grew by $12 \%$, white skin by $1 \%$, and Asians by $4 \%$ after 7 days [18]. According to a report, basal keratinocytes in type III (French) skin lacked nuclear melanin capping in subjects tanned during their vacation time [19]. Recently, this has also been observed in Japanese individuals. This implies that the tanning process's first stages are the most crucial and are caused by the redistribution of already established melanin, and melanosomes that have already been synthesized are transferred to suprabasal keratinocytes. Human photobiology research has traditionally focused on UV radiation and, more recently, on visible light [20]. Visible light has wavelengths ranging from 400 to $700 \mathrm{~nm}$, while it has been classified as covering the range of 380$780 \mathrm{~nm}$ CIE in various European Commission docu- ments. In human skin, visible light has been shown to cause both transitory and long-term pigmentations [21]. Visible light-induced pigmentation has been demonstrated to last up to 8 weeks, and the amount of pigment created is proportional to the overall dose of light. A study of the effects of visible light on human skin, particularly in persons with darker complexions, found that the induction of pigmentation was not accompanied by any negative effects similar to those caused by UV radiation [20]. In contrast to these findings, Liebel et al. [22] demonstrated that visible light can cause considerable ROS generation in skin, resulting in the release of pro-inflammatory cytokines and the development of matrix metalloproteinases. A single UVB exposure can cause delayed pigment development, which is preceded by an erythema reaction. During the first minutes of exposure, UVA (320-400 nm) can cause immediate pigment darkening (IPD), which is a temporary kind of pigmentation that fades away within a few hours $[23,24]$, or persistent pigment darkening, which is a pigment darkening that emerges within hours of greater UVA exposure and lasts for several days or weeks $[25,26]$. Single UVA exposure 
Table 1. Assessment of skin color variations among the different populations by using several devices

\begin{tabular}{|c|c|c|c|c|}
\hline S. No & Authors & Condition studied & Population & Device \\
\hline 1 & Huixia et al. [36] & $\begin{array}{l}\text { Changes induced by whitening products, ITA, and } \\
\text { pigmentation and skin tone measurement }\end{array}$ & Asian (China) & Chromosphere \\
\hline 2 & Cust et al. [37] & $\begin{array}{l}\text { Nevus phenotype measurement and skin } \\
\text { pigmentation }\end{array}$ & Adults (Australia) & Spectrophotometer \\
\hline 3 & Clarys et al. [38] & Skin color measurement & Adults (Belgium) & $\begin{array}{l}\text { Dermaspectrometer, } \\
\text { Chromameter, Mexameter }\end{array}$ \\
\hline 4 & Stamatas et al. [39] & Pigmentation and in vivo skin erythema & $\begin{array}{l}\text { White, Asian, Hawaiians or other Pacific } \\
\text { Islanders, African-American, Latino, or } \\
\text { Hispanic }\end{array}$ & Spectrophotometer \\
\hline 5 & Xiao et al. [40] & Variation in skin color measurement & Kurdish, Thai (UK), Chinese, Caucasian & Spectrophotometer \\
\hline 6 & Nam et al. [41] & Skin brightness measurement & Adults (Korea), Asian & Spectrophotometer \\
\hline 7 & Everett et al. [42] & Skin color measurement & $\begin{array}{l}\text { Asian, black or African-American, white, mixed } \\
\text { origin (USA) Asian, black or African-American, } \\
\text { Biracial (USA), white }\end{array}$ & Spectrophotometer \\
\hline 8 & Wright et al. [43] & ITA and skin color measurement & Children (New Zealand) & $\begin{array}{l}\text { Spectrophotometer } \\
\text { Munsell color chart }\end{array}$ \\
\hline 9 & Weatherall and Coombs [44] & Skin color measurement & $\begin{array}{l}\text { Indian, Polynesian, mixed origin, Europeans, } \\
\text { Chinese }\end{array}$ & Spectrophotometer \\
\hline 10 & Park et al. [45] & $\begin{array}{l}\text { Skin color changes after UVB and UVA, ITA, skin color } \\
\text { measurement }\end{array}$ & Asian (Korea) & Spectrophotometer \\
\hline 11 & Chardon et al. [46] & ITA, tanning. and skin color measurement & Caucasian (France) & Spectrophotometer \\
\hline 12 & Chien et al. [47] & Pigmentation in aging & African-American (USA), Caucasian & Chromameter \\
\hline 13 & Del Bino and Bernard [48] & $\begin{array}{l}\text { ITA, UVR responses in ex vivo skin, skin color } \\
\text { measurement }\end{array}$ & $\begin{array}{l}\text { African descent, Asian, Caucasian, and } \\
\text { Hispanic; adults (USA, France, Russia, Brazil, } \\
\text { Japan, China, India, Thailand) }\end{array}$ & Spectrophotometer \\
\hline 14 & Alaluf et al. [7] & Epidermal melanin impact on human skin color & $\begin{array}{l}\text { Indian, black (South Africa), European, } \\
\text { Mexican, Chinese }\end{array}$ & Chromameter \\
\hline 15 & Wright et al. [49] & ITA, skin color measurement, and erythema sensitivity & $\begin{array}{l}\text { Indian or Asian, white, mixed origin (South } \\
\text { Africa), black }\end{array}$ & Colorimeter \\
\hline
\end{tabular}

UVR, ultraviolet radiation; ITA, individual typology angle.

has been proven to cause IPD and persistent pigment darkening, as well as erythema, in skin phototypes I and II [27], and some research in fair-skinned people has looked into the pigmentation growth following frequent UVA exposures [28-30]. Several reviews observed pigment changes accompanied by erythema. Researchers exposed people with skin types II, III, and IV to visible light and saw IPD, acute erythema, and a long-lasting delayed tanning reaction [31]. In their review, Mahmoud et al. [31] speculated that the discrepancy could be related to the use of nonstandardized light sources in investigations on the effects of visible light on human skin pigmentation, as well as the lack of such sources.

Nonetheless, as determined by p53 levels, 6-4 photoproducts, and cyclobutane pyrimidine dimers, photo- damage affects all SPTs to some extent [18]. Bonnet Duquennoy et al. [32] identified increased levels of p53 in Chinese subjects $24 \mathrm{~h}$ after one minimal erythemal dose, and in comparison with sun-protected skin, these levels were higher in sun-exposed skin. Similarly, de Winter et al. [33] found that a single UV exposure in the epidermis increased the immunoreactivity of $\mathrm{p} 53$, with elevated levels in darker-skinned people. Similarly, in response to DNA damage, DNA repair enzymes are known to be upregulated by this tumor suppressor gene and regulate cell cycle progression, allowing for additional time for DNA repair. It also causes apoptosis in cells that have been severely damaged. The removal of cyclobutane pyrimidine dimers is less effective in the skin with light pigmentation. According to Wagner et al. [8], a significantly lower tanning 
Table 2. Association of genes and their function in the African population

\begin{tabular}{lllll}
\hline S. No & SNP & Allele & Gene & Function \\
\hline 1 & rs10424065 & T & MFSD12 & Intronic \\
2 & rs56203814 & T & MFSD12 & Synonymous \\
3 & rs2240751 & G & MFSD12 & Tyr 182 His \\
4 & rs7948623 & T & DDB1 & Intergenic \\
5 & rs6497271 & G & HERC2 & Intronic \\
6 & rs4932620 & T & HERC2 & Intronic \\
7 & rs1800404 & T & OCA2 & Synonymous \\
8 & rs12913832 & A & HERC2 & Intronic \\
9 & rs1426654 & A & SLC24A5 & Ala 111 Thr \\
\hline
\end{tabular}

SNP, single-nucleotide polymorphism.

response than East Asians and Hispanics and European Americans with low constitutive pigmentation had a much larger burn reaction indicating that they burnt more and browned less than those with higher pigmentation. In this line, Rijken et al. [34] analyzed white and black skin responses to solar-simulating radiation. They discovered that, unlike Caucasians, participants with skin color did not reveal any diffuse keratinocyte activation, active proteolytic enzymes or increase in neutrophils, and the suprabasal epidermis, except for minor DNA damage. As a result, other than melanin, Asian skin appears to have systems to protect against UV irradiation. It is probably due to dietary factors, but it is also possible to link to the DNA repair enzymes and p53 induction [35]. Several devices were used to assess skin color variations among different populations, listed in Table 1.

\section{Genetics of Skin Color}

Heritability overall is the most crucial issue for any quantitative trait with multiple contributing components, the number of genes that are likely to be implicated, and the most effective methods for identifying specific genes. The broad-sense heritability of skin color is very high [50], provided one can account for sunlight exposure as the most crucial nongenetic component. Several pieces of research have made claims about the number of genes in the skin color of humans; one of the most comprehensive is by Harrison and Owen [51] who evaluated the skin reflectance measurements among 70 Liverpool inhabitants who were their grandparents, parents or both were of European or West African ancestry and who were divided into "backcross" and "hybrid" classes based on this. An effort to partition and evaluate the backcross

Influence of Ethnicities and Skin Color

Variations in Different Populations groups' variance yielded marginal estimations of 3-4 "efficient variables," in this case, segregating genes independently. To put it another way, the average skin reflectance of "backcross hybrid" groups is half that of their parental groups. One of the earliest models to identify and investigate gene function and interaction was mouse coat color genetics, which has been used to consider the number of possible human pigmentation genes. Approximately, 100 different genes have been identified for mouse coat color genetics [52].

In nontropical populations, especially among Europeans, the MCIR gene has a wide range of alleles, but these alleles primarily affect hair color. Only red hair is linked to a decrease in skin pigmentation [53]. The Arg163Gln version of the gene is found in most Japanese and Inuits, while red-haired people have a variety of other variants, including Arg160Trp and Arg151Cys. The ASIP gene can influence light and dark pigmentation in people all over the world. The production of light skin appears to be influenced by a variety of genes: $D R D 2, E G F R, D C T$, and KITLG in Asians; KITLG, SLC24A5, TYRP1, DTNBP1, and MYO5A in Europeans; and SLC24A5 which is responsible for $25-38 \%$ of the variation in skin color between Africans and Europeans $[53,54]$. Several genes and their functions were associated with the African population listed in Table 2.

\section{Role of Vitamin D}

Vitamin D is synthesized in the human skin, which also serves as a target organ for the biologically active version of the vitamin. Vitamin D has an impact on a variety of skin activities, including apoptosis, differentiation, and keratinocyte proliferation, as well as immunoregulatory mechanisms and barrier maintenance. Vitamin D is also being evaluated as a treatment option for a variety of skin conditions [55]. Vitamin D has been found to have a dosedependent influence on keratinocyte proliferation and differentiation in numerous in vitro investigations. $1,25(\mathrm{OH}) 2 \mathrm{D} 3$ was found to stimulate keratinocyte proliferation at low concentrations (10-9M or less), but inhibited proliferation and promoted differentiation at high concentrations $(>10-8 \mathrm{M})[56,57]$. The effect of vitamin D on in vitro keratinocyte proliferation is influenced by a number of other parameters, including calcium concentrations, cell density, and the absence or presence of serum [58]. Vitamin $\mathrm{D}$ has a dose-dependent influence on keratinocyte apoptosis, similar to its effect on cellular growth. Vitamin D protects apoptosis produced by different proapoptotic stimuli such as TNF, UV radiation, ceramide, and others at normal quantities, whereas it causes apoptosis in keratinocytes 
at high concentrations [58]. The Tanzanian Hadza, a darkskinned hunter-gatherer population who live traditionally and expose much of their skin to intense sun, have a high vitamin D status, with typical 25(OH)D3 blood levels in the order of $110 \mathrm{nmol} / \mathrm{L}$ [59].

Antimicrobial peptide synthesis has been reported to be regulated by vitamin $\mathrm{D}$ through mechanisms other than direct transcriptional activation. Serine proteases KLK5 and KLK7 regulate the action of cathelicidin and other antimicrobial peptides in human skin [60]. Vitamin D also plays a vital role in the development of certain inflammatory skin diseases. Many observational studies, including a meta-analysis, have found that levels of serum vitamin $\mathrm{D}$ are lower in adults and children with atopic dermatitis $(\mathrm{AD})$ than in controls and that vitamin $\mathrm{D}$ insufficiency is linked to the risk of atopic eczema [61-63]. Many investigations have found a shortage or insufficiency of serum vitamin $\mathrm{D}$ in psoriatic patients, indicating that vitamin D plays an important role in the disease [64, 65]. Several case-control studies have found that psoriatic patients have significantly lower levels of serum $25(\mathrm{OH}) \mathrm{D}$ than controls, as well as an inverse relationship between serum $25(\mathrm{OH}) \mathrm{D}$ and disease severity $[66,67]$. Future studies, utilizing the most current technology, will be required to mechanistically and intensively investigate the particular pathways influenced by vitamin $\mathrm{D}$ and to determine the efficacy and safety of vitamin D-based treatment regimens in the treatment of a variety of inflammatory skin conditions.

\section{The Influence of Skin Color on the Skin Structure}

Skin color is influenced by the type of melanin present, UV exposure, genetics, the content of melanosomes, and other chromophores in the skin [16]. The presence of various 4 chromophore combinations influences skin color perception in part: carotenoids, melanin, oxyhemoglobin, and hemoglobin. Because of the different light reflections and absorption caused by the mixture of these chromophores, the skin appears in various shades. The combination of oxyhemoglobin and hemoglobin developed a pink color in white skin, and the interaction of melanin and carotenes developed a yellow-orange color in brown skin [68]. Melanocytes are skin cells that produce the color melanin. Melanosomes are the organelles within melanocytes that create, deposit, and transmit melanin pigment. Skin color variances are caused by changes in the size, volume, and keratinocyte and melanocyte distributions, not by variances in the number of melanocytes between ethnic groups $[69,70]$. Lightly colored skin has smaller melanosomes clustered in secondary lysosomes, whereas darkly colored skin has larger melanosomes scattered singly within lysosomes. The varied hues of skin color that exist even within ethnic groups are due to changes in melanosome density and size, with varied proportions of larger single dispersed melanosomes and smaller aggregated melanosomes based on the pigmentation degree [70].

Skin color affects the position of melanosomes within the epidermis. Melanosomes are found throughout the epidermis, but in darkly colored skin, they are concentrated and evenly distributed over the basal layer, whereas melanosomes break down more quickly in white skin, resulting in noticeable absence in the epidermis' upper layers and small clusters of melanosomes in the Malpighian layers and basal cells [71]. Compared to lighter shaded black skin, more basal layer melanosomes are found in darkly colored black skin within an ethnic group. Similar conclusions are obtained when darker white skin and darker Asian skin are compared to their lighter equivalents [72]. Other components of melanogenesis differ depending on skin color, resulting in changes in melanin synthesis. The optimal $\mathrm{pH}$ for melanin synthesis is 6.8 , which black skin's melanosomes come near, whereas white skin's melanosomes have a more acidic $\mathrm{pH}$ [73]. Melanosome transport to keratinocytes is another biological mechanism that affects pigmentation. This process is mediated by the protease-activated receptor 2. Compared to lighter pigmented skin, proteaseactivated receptor 2 is found in greater abundance in darker pigmented skin. Additionally, the induction of proteaseactivated receptor 2 is delayed in lighter skin [74].

In hyperpigmentation development, the enhanced activity of protease-activated receptor 2 could have a role, which is more common in those with darker skin. Aside from pigmentation, changes in the dermis of skin and epidermis structure of different colors have been observed. Differential responses to aging have been related to the reduction in epidermal structure across skin colors. Sun-exposed black skin, for example, has a more compact stratum lucidum, whereas sun-exposed white skin has a more hypercellular and edematous stratum lucidum. The epidermis of intensely pigmented samples is low dyskeratotic and vacuolated compared to samples of the epidermis of more minor pigmented. Although there is no discernible skin thickness difference between white and black skin, black skin possesses more corneocytes in the stratum corneum than white skin, implying a more dense and compacted layer $[75,76]$. Black skin has a higher mean electrical resistance than white skin, which is most likely due to this compaction [77]. According to further research, in white, black, and Asian skin, the corneocytes 
are all the same size, and there are no differences in the maturation of corneocytes, according to further research [78]. The epidermis appears to have the highest ceramide concentration in Hispanic and Asian skin and low concentration in black skin $[79,80]$. There was no change in the surface of skin pH between the ethnic groups $[81,82]$. On black skin, Candida albicans, Cutibacterium acnes, and aerobic bacteria are all more common than on white skin [83].

\section{Skin Color as It Influences Skin Function}

Small sample sizes, inadequate study designs, and contradicting results have hampered investigations into functional variations in the skin between individuals of different skin hues. Two investigations comparing the absorption of topical medicines through black and white skin found no differences in percutaneous absorption $[84,85]$, whereas 3 other investigations found that black skin inhibited the absorption of topical medicines [86]. There were no variations in absorption between white and Hispanic skin in research [87], but in a study comparing Asian skin to white skin, it was discovered that Asian skin absorbs less than white skin [88]. While there were no significant variations in skin physiological characteristics, morphological study of hair follicles found that Caucasians had much larger terminal hair follicles than Asians and Africans, among other things [89].

Erythema is a subjective criterion impacted by skin color, and it is typically misunderstood in pigmented skin. According to studies that employ erythema as an endpoint, lighter white skin is the most vulnerable and black skin is less susceptible to contact irritants than white skin $[90,91]$. One explanation why black nursing home residents are 2-4 times more likely than white patients to develop decubitus ulcers has been suggested: it is challenging to recognize erythema in darker skin colors [92]. Transepidermal water loss as a function of stratum corneum integrity is another endpoint used to measure skin irritation. Even when employing this criterion, the results have been mixed, with some research claiming that white skin is more inflamed than Asian and black skin [93], whereas others find no difference between groups [94]. The primary endpoint was skin water vapor loss; a study comparing 11 dark-skinned Indians, 12 dark-skinned Malaysians, and 15 light-skinned Chinese patients found no significant differences in skin irritation across the groups. When patients were asked to self-assess their skin, there was no variation in the incidence of sensitive skin by ethnic group [95]. UV radiation damages skin in variable degrees, regardless of pigment. The num-

Influence of Ethnicities and Skin Color Variations in Different Populations ber of pyrimidine dimers and 6-4 photoproducts formed in UV-exposed cells' DNA can be used to measure the extent of the damage, as well as the activity of the p53 gene in those cells [18]. This gene acts to prevent the development of cancer and tumor suppressor. According to studies, black skin has higher $\mathrm{p} 53$ gene activity than white skin following UV exposure [33]. When Asian skin was compared to white skin, a similar outcome was found [32], implying that this gene's activation is one of the mechanisms that protect different skin types from developing skin malignancies [96].

\section{Prevalence of Skin Disorders between Ethnic Groups}

The top 5 dermatologic diagnoses made by dermatologists in the USA have been ranked according to population: dyschromia, seborrheic dermatitis, acne, dermatitis, and $\mathrm{AD}$ are the top 5 diagnoses in black communities; benign neoplasms, psoriasis, warts, acne, and dermatitis are the top 5 diagnoses in Hispanic populations and seborrheic keratosis, acne, benign neoplasms, dermatitis, and psoriasis are the top 5 diagnoses in Asian communities, while nonmelanoma skin cancer, acne, actinic keratoses, dermatitis, and benign neoplasms are the top $5 \mathrm{di}$ agnoses in white people [97]. Melanoma is more common in nonsun-exposed parts of the body, such as the palms and soles, in black, Hispanic, and Asian people, with acral lentiginous melanoma being the most prevalent kind of melanoma in these groups. Compared to white receivers, malignant neoplasms that develop in black and Hispanic transplant patients are more likely to appear in sun-protected areas [98].

In nonwhite populations, melanoma is more likely to be identified after spreading and has a poor prognosis. Black individuals have a $66.7 \%$ 5-year melanoma survival rate compared to $92.5 \%$ for white patients. These disparities are presumably the result of several socioeconomic variables, including educational gaps, health-care professional education gaps, and health-care access disparities. Keloids are a scarring phenomenon that varies in occurrence by ethnic group, though it is unclear if this is due to skin color or other causes. The incidence of keloids is higher in black patients than white patients [99] and higher in Chinese patients than Indian and Malaysian patients [100]. As previously stated, determining whether or not there is an actual difference in contact dermatitis prevalence between ethnic groups has proven problematic, probably due to most research using erythema as the endpoint [101]. Compared to white people, Asian and black people are more likely to develop $\mathrm{AD}$, especially in youngsters. The odds ratio of developing AD is 1.9 for Hispan- 
ics, 2.2 for black patients, and 3.1 for Asians. Even when sociodemographic characteristics and vitamin D levels are considered, this preponderance remains [102]. Because much of the evidence for systemic therapy for $\mathrm{AD}$ in the USA has typically been based on randomized studies conducted in Europe, where ethnic diversity is lower than in the USA, making it difficult to generalize the results, the gap in prevalence has significant implications for treatment [103].

\section{Modern Eurasians' Skin Color Adaptation}

The golden genes SLC45A2 and SLC24A5 are connected to Europeans' light skin color development [104, 105]. The NCKX5 protein, a transmembrane protein that regulates calcium concentration in the melanosome, belongs to the transmembrane protein family encoded by SLC24A5 [106]. In zebra fish and mice, pigmentation is influenced by this gene [107]. In SLC24A5, the derived allele of rs1426654 was nearly fixed in Europeans but virtually missing in groups without European ancestry [108]. In Europeans, a 78-kb haplotype around SLC24A5, which is in linkage disequilibrium with rs1426654, has been discovered to accumulate [109]. Many animals, including birds, horses, fish, and mice, have a similar pattern at rs16891982 in SLC45A2, associated with pigmentation $[110,111]$. In Europeans, other variants in this gene, such as rs40132, rs2287949, and rs26722, have also been associated with coloration $[109,112]$. Melanocortin 1 receptor $(M C 1 R)$ is another essential pigmentation-related gene discovered in Europeans [113]. This gene is found in melanocytes and controls the transition from pheomelanin to eumelanin [114]. In a range of animal species, pigmentary traits connected to $M C 1 R$ have been studied $[115,116]$. Despite its small size (951 bp), MC1R has a large number of variants, including rs1805008, rs3212357, and rs1805007 [117, 118]. The rs1900758 in OCA2, rs2733831 in TYRP1, and rs1393350 in TYR are other important European-specific loci $[119,120]$. According to statistical analysis, the frequencies of derived alleles at these loci are higher in Europeans but lower in East Asians and Africans, suggesting that Europeans have been subjected to positive selection [121].

Genes involved in the adaptation of skin color in East Asians have received less attention than genes involved in skin color adaptation in Europeans. MC1R and OCA2 are 2 well-known examples. The rs885479 in MC1R and rs 1800414 and rs74653330 in OCA2 are examples of nonsynonymous mutations $[122,123]$, which have high derived allele frequencies in East Asians but low-derived allele frequencies in Europeans and Africans. The OCA2 pro- tein is assumed to be a mature membrane protein found on melanosomes. That may help transport proteins into melanosomes [124]. In a study of Han Chinese people using the melanin index to measure skin color, the skin lightening was assumed to be caused by the derived allele at rs 1800414 [125]. Another pigmentation-related nonsynonymous variation in OCA2, rs74653330, was discovered [126]. The rs1407995 in DCT and rs10809814 in TYRP1 are 2 more pigmentation-related alleles specific to East Asians that display a difference between non-Asians and Asians [125], and Asians show signs of positive selection are very strong [127].

\section{The Admixed Populations' Skin Color Adaptation}

Because their ancestral groups have such a wide range of skin colors, current study into pigmentation genes in admixed people is essential and mainly included those with European and African ancestry, such as Latin Americans, European Africans, and African-Americans. These 3 populations have different ancestral genetic makeups. Mestizos from Latin America have the smallest percentage of African ancestry $(\sim 10 \%)$. African-Americans had the highest genetic contribution from their African ancestors $(\sim 80 \%)[128,129]$, while in European Africans, the genetic components inherited from Europeans ( $42 \%)$ and Africans ( $58 \%)$ are comparable [130]. Native American ancestry accounts for a large share of the population $(\sim 45 \%)$ occur in Latin Americans, which is unique $[129,131]$. Furthermore, the proportion of ancestry in each admixed population varies significantly on an individual basis. For example, among African-Americans, the percentage of European ancestry ranges from 2 to $98 \%$ [128]. Since there is a strong link between ancestry proportion and skin color in admixed people, their wide skin color may be due to their highly diverse genetic makeup [130, 132]. Admixture mapping or interaction studies in admixed populations have also identified many well-known pigmentation candidate genes in Europeans. For example, tyrosinase (TYR) has the rs1042602 nonsynonymous substitution (S192Y), which was identified in European Africans from Cape Verde [130] and African-Americans [133]. Variants in Agouti-signaling protein (ASIP), such as rs6058017, have been found in various populations around the world at varied rates [134] and were also reported to be connected with brown eyes and dark hair in European Americans, Brazilians, and AfricanAmericans [15]. Furthermore, in African-Americans, KITLG displayed strong selective sweep signals, and people with a high melanin index have a marked prefer-
Naik/Farrukh 
ence for homozygotes of the African-specific gene (ancestral allele) at rs642742 (dark skin) [133].

However, some research represents contradictory findings. There is a connection between Native American ancestry and skin pigmentation in a Hispanic population that was not observed in a group of Puerto Rican women [132]. When tested in African-Americans and a combined population of African-Caribbeans and AfricanAmericans, one of the critical single-nucleotide polymorphism loci in OCA2, rs 1800404, had a significant impact on skin pigmentation but was absent in an independent investigation of African-Caribbean samples [133]. It is crucial to note that distinct genetic pathways for skin color variation exist in different populations; however, when evaluating detailed data, including ancestral populations and sample size utilized to evaluate admixed populations, caution should be exercised, as these could lead to skewed results $[129,133]$.

\section{Current Trends in Improvement of Skin Color}

In cosmetics, beauty therapy, and dermatology, current applications for the treatment of skin pigmentation defects and the enhancement of skin tone are relevant aspects. Inhibition of enzymes involved in various stages of melanogenesis, such as microphthalmia transcription factor (MITF), TYR, MC1R, laser therapies, ultrasound, dermabrasion, exfoliation, destruction of melanocytes, interfering with melanosomal maturation and melanin transfer and melanosomes' number and size. Effective treatments typically incorporate 2 or more approaches that have a synergistic effect. Active ingredients are chosen for their ability to monitor pigmentation while staying low in toxicity from both natural and synthetic sources [135]. The comprehensive structure-activity relationship studies will also be used to identify new and advanced combinations of ingredients with given therapeutic profiles and mechanisms. Although all of these applications inhibit melanogenesis, just a few made it to the commercial product due to clinical trials, cutaneous absorption, and cytotoxicity $[136,137]$.

\section{Conclusion}

Skin color unquestionably impacts the composition and microenvironment activity. Therefore, the contrast of dermatological ailments between distinct race-related categories is remarkable. Skin color adaptation is a challenging procedure since different populations have shared and separate genetic processes involving many genes with different impact advantages on the phenotypes. An enormous collection of phenotype data and high-coverage whole-genome sequences could help researchers develop more accurate gene-environment interactions and genetic architecture models and learn more about minor ethnic groups. Refinement of skin color is an age-old craving of humans with ever-evolving drifts.

\section{Conflict of Interest Statement}

The authors have no conflicts of interest to declare.

\section{Funding Sources}

The authors have no funding sources to declare.

\section{Author Contributions}

Both authors contributed equally to conception, preparing, drafting, editing, revising, finalizing, and approving the manuscript.

\section{References}

1 Chen H-Y, Jablonski NG. Deeper than the surface: exploring symbolic cultural cues behind skin color among three groups of women of Chinese heritage. Am J Cult Sociol. 2021 Jan. Epub ahead of print.

2 Ito S, Wakamatsu K. Quantitative analysis of eumelanin and pheomelanin in humans, mice, and other animals: a comparative review. Pigment cell Res. 2003;16(5):523-31.
3 Hennessy A, Oh C, Diffey B, Wakamatsu K, Ito $\mathrm{S}$, Rees J. Eumelanin and pheomelanin concentrations in human epidermis before and after UVB irradiation. Pigment cell Res. 2005;18(3):220-3.

4 Barsh GS. What controls variation in human skin color? PLoS Biol. 2003;1(1):e27.

5 Tennessen JA, Akey JM. Parallel adaptive divergence among geographically diverse human populations. PLoS Genet. 2011;7(6): e1002127.
6 Gautam P, Chaurasia A, Bhattacharya A, Grover R, Consortium IGV, Mukerji M, et al. Population diversity and adaptive evolution in keratinization genes: impact of environment in shaping skin phenotypes. Mol Biol Evol. 2015;32(3):555-73.

7 Alaluf S, Atkins D, Barrett K, Blount M, Carter N, Heath A. The impact of epidermal melanin on objective measurements of human skin colour. Pigment cell Res. 2002;15(2): $119-26$.
Influence of Ethnicities and Skin Color Variations in Different Populations
Skin Pharmacol Physiol 2022;35:65-76 DOI: $10.1159 / 000518826$ 
8 Wagner JK, Jovel C, Norton HL, Parra EJ, Shriver MD. Comparing quantitative measures of erythema, pigmentation and skin response using reflectometry. Pigment cell Res. 2002;15(5):379-84.

9 Sturm RA, Box NF, Ramsay M. Human pigmentation genetics: the difference is only skin deep. Bioessays. 1998;20(9):712-21.

10 ReesJL. The melanocortin 1 receptor (MC1R): more than just red hair. Pigment Cell Res. 2000;13(3):135-40.

11 Juzeniene A, Stokke KT, Thune P, Moan J. Pilot study of folate status in healthy volunteers and in patients with psoriasis before and after UV exposure. J Photochem Photobiol B. 2010;101(2):111-6.

12 Brenner M, Hearing VJ. The protective role of melanin against UV damage in human skin. Photochem Photobiol. 2008;84(3):539-49.

13 Greaves M. Was skin cancer a selective force for black pigmentation in early hominin evolution? Proc Biol Sci. 2014;281(1781): 20132955.

14 Hart PH, Gorman S, Finlay-Jones JJ. Modulation of the immune system by UV radiation: more than just the effects of vitamin $D$ ? Nat Rev Immunol. 2011;11(9):584-96.

15 Deng L, Xu S. Adaptation of human skin color in various populations. Hereditas. 2018 Dec;155(1):1.

16 Taylor SC. Skin of color: biology, structure, function, and implications for dermatologic disease. J Am Acad Dermatol. 2002 Feb;46(2): S41-62.

17 Dell'Angelica EC. Melanosome biogenesis: shedding light on the origin of an obscure organelle. Trends Cell Biol. 2003;13(10):503-6.

18 Tadokoro T, Kobayashi N, Zmudzka BZ, Ito S, Wakamatsu K, Yamaguchi Y, et al. UV-induced DNA damage and melanin content in human skin differing in racial/ethnic origin. FASEB J. 2003;17(9):1177-9.

19 Corcuff P, Chaussepied C, Madry G, Hadjur C. Skin optics revisited by in vivo confocal microscopy: melanin and sun exposure. J Cosmet Sci. 2001;52(2):91-102.

20 Mahmoud BH, Ruvolo E, Hexsel CL, Liu Y, Owen MR, Kollias N, et al. Impact of longwavelength UVA and visible light on melanocompetent skin. J Invest Dermatol. 2010 Aug; 130(8):2092-7.

21 Kollias N, Baqer A. An experimental study of the changes in pigmentation in human skin in vivo with visible and near infrared light. Photochem Photobiol. 1984 May;39(5):651-9.

22 Liebel F, Kaur S, Ruvolo E, Kollias N, Southall MD. Irradiation of skin with visible light induces reactive oxygen species and matrix-degrading enzymes. J Invest Dermatol. 2012 Jul; 132(7):1901-7.

23 Miyamura Y, Coelho SG, Wolber R, Miller SA, Wakamatsu K, Zmudzka BZ, et al. Regulation of human skin pigmentation and responses to ultraviolet radiation. Pigment cell Res. 2007 Feb;20(1):2-13.
24 Routaboul C, Denis A, Vinche A. Immediate pigment darkening: description, kinetic and biological function. Eur J Dermatol. 1999 Mar;9(2):95-9.

25 Wolber R, Schlenz K, Wakamatsu K, Smuda C, Nakanishi Y, Hearing VJ, et al. Pigmentation effects of solar-simulated radiation as compared with UVA and UVB radiation. Pigment Cell Melanoma Res. 2008 Aug;21(4):487-91.

26 Suh KS, Roh HJ, Choi SY, Jeon YS, Doh KS, $\mathrm{Bae} \mathrm{JH}$, et al. Long-term evaluation of erythema and pigmentation induced by ultraviolet radiations of different wavelengths. Skin Res Technol. 2007 May;13(2):154-61.

27 Ruvolo E, Chu M, Grossman F, Cole C, Kollias $N$. Diffuse reflectance spectroscopy for ultraviolet A protection factor measurement: correlation studies between in vitro and in vivo measurements. Photodermatol Photoimmunol Photomed. 2009 Dec;25(6):298-304.

28 Miller SA, Coelho SG, Zmudzka BZ, Bushar HF, Yamaguchi Y, Hearing VJ, et al. Dynamics of pigmentation induction by repeated ultraviolet exposures: dose, dose interval and ultraviolet spectrum dependence. Br J Dermatol. 2008 Oct;159(4):921-30.

29 Bech-Thomsen N, Ravnborg L, Wulf HC. A quantitative study of the melanogenic effect of multiple suberythemal doses of different ultraviolet radiation sources. Photodermatol Photoimmunol Photomed. 1994 Apr;10(2): 53-6.

30 Ravnbak MH, Philipsen PA, Wiegell SR, Wulf HC. Skin pigmentation kinetics after UVB exposure. Acta Derm Venereol. 2008;88(3): 223-8.

31 Mahmoud BH, Hexsel CL, Hamzavi IH, Lim HW. Effects of visible light on the skin. Photochem Photobiol. 2008;84(2):450-62.

32 Bonnet Duquennoy M, Lachmann N, Noblesse E, Pincemail J, Kurfurst R, Bonte F. Influence of UV exposure on DNA damage in Chinese skin. Int J Cosmet Sci. 2005;27(1):69-73.

33 de Winter S, Vink AA, Roza L, Pavel S. Solarsimulated skin adaptation and its effect on subsequent UV-induced epidermal DNA damage. J Invest Dermatol. 2001;117(3):678-82.

34 Rijken F, Bruijnzeel PL, van Weelden $\mathrm{H}$, Kiekens RC. Responses of black and white skin to solar-simulating radiation: differences in DNA photodamage, infiltrating neutrophils, proteolytic enzymes induced, keratinocyte activation, and IL-10 expression. J Invest Dermatol. 2004 Jun;122(6):1448-55.

35 Hasan JM, Gaaib JN, Mahdi MG. HERC2 rs12913832 association with eye, hair and skin color in the Iraqi population. Sci J Med Res. 2021;5(17):16-9.

36 Huixia Q, Xiaohui L, Chengda Y, Yanlu Z, Senee J, Laurent A, et al. Instrumental and clinical studies of the facial skin tone and pigmentation of Shanghaiese women. Changes induced by age and a cosmetic whitening product. Int J Cosmet Sci. 2012;34(1):49-54.
37 Cust AE, Pickles KM, Goumas C, Vu T, Schmid H, Nagore E, et al. Accuracy of selfreported nevus and pigmentation phenotype compared with clinical assessment in a population-based study of young Australian adults. Cancer Epidemiol Biomarkers Prev. 2015; 24(4):736-43.

38 Clarys P, Alewaeters K, Lambrecht R, Barel AO. Skin color measurements: comparison between three instruments: the Chromameter $^{\circledR}$, the DermaSpectrometer ${ }^{\circledR}$ and the Mexameter ${ }^{\circledR}$. Ski Res Technol. 2000 Nov;6(4): 230-8.

39 Stamatas GN, Zmudzka BZ, Kollias N, Beer JZ. In vivo measurement of skin erythema and pigmentation: new means of implementation of diffuse reflectance spectroscopy with a commercial instrument. Br J Dermatol. 2008; 159(3):683-90.

40 Xiao K, Yates JM, Zardawi F, Sueeprasan S, Liao N, Gill L, et al. Characterising the variations in ethnic skin colours: a new calibrated data base for human skin. Skin Res Technol. 2017;23(1):21-9.

41 Nam GW, Baek JH, Koh JS, Hwang JK. The seasonal variation in skin hydration, sebum, scaliness, brightness and elasticity in Korean females. Skin Res Technol. 2015;21(1):1-8.

42 Everett JS, Budescu M, Sommers MS. Making sense of skin color in clinical care. Clin Nurs Res. 2012;21(4):495-516.

43 Wright CY, Reeder AI, Gray AR, Hammond VA. Comparison of Munsell $\left({ }^{\circledR}\right)$ color chart assessments with primary schoolchildren's self-reported skin color. Skin Res Technol. 2015;21(4):459-65.

44 Weatherall IL, Coombs BD. Skin color measurements in terms of CIELAB color space values. J Invest Dermatol. 1992;99(4):468-73.

45 Park S-B, Huh C-H, Choe Y-B, Youn J-I. Time course of ultraviolet-induced skin reactions evaluated by two different reflectance spectrophotometers: DermaSpectrophotometer $^{\circledR}$ and Minolta spectrophotometer CM$2002^{\circledR}$. Photodermatol Photoimmunol Photomed. 2002 Feb;18(1):23-8

46 Chardon A, Cretois I, Hourseau C. Skin colour typology and suntanning pathways. Int $\mathrm{J}$ Cosmet Sci. 1991;13(4):191-208.

47 Chien AL, Suh J, Cesar SSA, Fischer AH, Cheng N, Poon F, et al. Pigmentation in African American skin decreases with skin aging. J Am Acad Dermatol. 2016;75(4):782-7.

48 Del Bino S, Bernerd F. Variations in skin colour and the biological consequences of ultraviolet radiation exposure. $\mathrm{Br} J$ Dermatol. 2013;169 Suppl 3:33-40.

49 Wright CY, Wilkes M, Du Plessis JL, Reeder AI. Self reported skin colour and erythemal sensitivity vs. objectively measured constitutive skin colour in an A frican population with predominantly dark skin. Photodermatol Photoimmunol Photomed. 2015;31(6):31524.

50 Clark P, Stark AE, Walsh RJ, Jardine R, Martin NG. A twin study of skin reflectance. Ann Hum Biol. 1981;8(6):529-41. 
51 Owen $\mathrm{H}$. Studies on the inheritance of human skin colour. Ann Hum Genet. 1964 Sep;28(13):27-37.

52 Bennett DC, Lamoreux ML. The color loci of mice - a genetic century. Pigment Cell Res. 2003;16(4):333-44.

53 Feng Y, McQuillan MA, Tishkoff SA. Evolutionary genetics of skin pigmentation in African populations. Hum Mol Genet. 2021 Apr; 30(R1):R88-97.

54 Juzeniene A, Setlow R, Porojnicu A, Steindal AH, Moan J. Development of different human skin colors: a review highlighting photobiological and photobiophysical aspects. J Photochem Photobiol B. 2009 Aug;96(2):93100.

55 Umar M, Sastry KS, Al Ali F, Al-Khulaifi M, Wang E, Chouchane AI. Vitamin D and the pathophysiology of inflammatory skin diseases. Skin Pharmacol Physiol. 2018;31(2):74-86.

56 Itin PH, Pittelkow MR, Kumar R. Effects of vitamin $\mathrm{D}$ metabolites on proliferation and differentiation of cultured human epidermal keratinocytes grown in serum-free or defined culture medium. Endocrinology. 1994 Nov; 135(5):1793-8.

57 Gniadecki R. Stimulation versus inhibition of keratinocyte growth by 1,25-dihydroxyvitamin D3: dependence on cell culture conditions. J Invest Dermatol. 1996 Mar;106(3) 510-6.

58 Schauber J, Gallo RL. Expanding the roles of antimicrobial peptides in skin: alarming and arming keratinocytes. J Invest Dermatol. 2007 Mar;127(3):510-2.

59 Luxwolda MF, Kuipers RS, Kema IP, van der Veer E, Dijck-Brouwer DA, Muskiet FA. Vitamin D status indicators in indigenous populations in East Africa. Eur J Nutr. 2013 Apr; 52(3):1115-25.

60 Yamasaki K, Schauber J, Coda A, Lin H, Dorschner RA, Schechter NM, et al. Kallikrein-mediated proteolysis regulates the antimicrobial effects of cathelicidins in skin. FASEB J. 2006 Oct;20(12):2068-80.

61 El Taieb MA, Fayed HM, Aly SS, Ibrahim AK. Assessment of serum 25-hydroxyvitamin d levels in children with atopic dermatitis: correlation with SCORAD index. Dermatitis. 2013;24(6):296-301.

62 Kim MJ, Kim SN, Lee YW, Choe YB, Ahn KJ. Vitamin D status and efficacy of vitamin D supplementation in atopic dermatitis: a systematic review and meta-analysis. Nutrients. 2016 Dec;8(12):789.

63 Yang A-R, Kim Y-N, Lee B-H. Dietary intakes and lifestyle patterns of Korean children and adolescents with atopic dermatitis: using the fourth and fifth Korean national health and nutrition examination survey (KNHANES IV,V), 2007-11. Ecol Food Nutr. 2016 Jan; 55(1):50-64.

64 Maleki M, Nahidi Y, Azizahari S, Meibodi NT, Hadianfar A. Serum 25-OH vitamin D level in psoriatic patients and comparison with control subjects. J Cutan Med Surg. 2016 May;20(3):207-10.
65 Mattozzi C, Paolino G, Salvi M, Macaluso L, Luci C, Morrone S, et al. Peripheral blood regulatory $\mathrm{T}$ cell measurements correlate with serum vitamin $\mathrm{D}$ level in patients with psoriasis. Eur Rev Med Pharmacol Sci. 2016;20: $1675-9$.

66 Orgaz-Molina J, Magro-Checa C, RosalesAlexander JL, Arrabal-Polo MA, CastelloteCaballero L, Buendía-Eisman A, et al. Vitamin $\mathrm{D}$ insufficiency is associated with higher carotid intima-media thickness in psoriatic patients. Eur J Dermatol. 2014 Jan;24(1): 53-62.

67 Ricceri F, Pescitelli L, Tripo L, Prignano F. Deficiency of serum concentration of 25-hydroxyvitamin D correlates with severity of disease in chronic plaque psoriasis. J Am Acad Dermatol. 2013;68(3):511-2.

68 Rawlings AV. Ethnic skin types: are there differences in skin structure and function? Int J Cosmet Sci. 2006;28(2):79-93.

69 Szabo G, Gerald AB, Pathak MA, Fitzpatrick TB. Racial differences in the fate of melanosomes in human epidermis. Nature. 1969; 222(5198):1081-2.

70 Olson RL, Gaylor J, Everett MA. Skin color, melanin, and erythema. Arch Dermatol. 1973; 108(4):541-4.

71 Montagna W, Carlisle K. The architecture of black and white facial skin. J Am Acad Dermatol. 1991;24(6):929-37.

72 Goldschmidt H, Raymond JZ. Quantitative analysis of skin color from melanin content of superficial skin cells. J Forensic Sci. 1972; 17(1):124-31.

73 Watabe H, Valencia JC, Yasumoto K, Kushimoto T, Ando H, Muller J, et al. Regulation of tyrosinase processing and trafficking by organellar $\mathrm{pH}$ and by proteasome activity. J Biol Chem. 2004;279(9):7971-81.

74 Scott G, Deng A, Rodriguez-Burford C, Seiberg M, Han R, Babiarz L, et al. Protease-activated receptor 2 , a receptor involved in melanosome transfer, is upregulated in human skin by ultraviolet irradiation. J Invest Dermatol. 2001;117(6):1412-20.

75 Bağcı IS, Ruini C, Niesert AC, Horváth ON Berking C, Ruzicka T, et al. Effects of shortterm moisturizer application in different ethnic skin types: noninvasive assessment with optical coherence tomography and reflectance confocal microscopy. Skin Pharmacol Physiol. 2018;31(3):125-33.

76 Weigand DA, Haygood C, Gaylor JR. Cell layers and density of Negro and Caucasian stratum corneum. J Invest Dermatol. 1974;62(6): 563-8.

77 Johnson LC, Corah NL. Racial differences in skin resistance. Science. 1963;139(3556):766-7.

78 Corcuff P, Lotte C, Rougier A, Maibach HI. Racial differences in corneocytes. A comparison between black, white and oriental skin. Acta Derm Venereol. 1991;71(2):146-8.

79 Sugino K, Imokawa G, Maibach HI. Ethnic difference of varied stratum corneum function in relation to stratum corneum lipids. J Dermatol Sci. 1993;6(1):108.
80 Jungersted JM, Høgh JK, Hellgren LI, Jemec GB, Agner T. Ethnicity and stratum corneum ceramides. Br J Dermatol. 2010 Dec;163(6): 1169-73.

81 Berardesca E, Pirot F, Singh M, Maibach H. Differences in stratum corneum $\mathrm{pH}$ gradient when comparing white Caucasian and black African-American skin. Br J Dermatol. 1998; 139(5):855-7.

82 Berardesca E, Maibach HI. Racial differences in sodium lauryl sulphate induced cutaneous irritation: black and white. Contact Dermatitis. $1988 ; 18(2): 65-70$.

83 Rebora A, Guarrera M. Racial differences in experimental skin infection with Candida albicans. Acta Derm Venereol. 1988;68(2):165-8.

84 Guy RH, Tur E, Bjerke S, Maibach HI. Are there age and racial differences to methyl nicotinateinduced vasodilatation in human skin? J Am Acad Dermatol. 1985 Jun;12(6):1001-6.

85 Wedig JH, Maibach HI. Percutaneous penetration of dipyrithione in man: effect of skin color (race). J Am Acad Dermatol. 1981 Oct; 5(4):433-8.

86 Kompaore F, Marty JP, Dupont C. In vivo evaluation of the stratum corneum barrier function in blacks, Caucasians and Asians with two noninvasive methods. Skin Pharmacol. 1993;6(3):200-7.

87 Berardesca E, Maibach H. Racial differences in skin pathophysiology. J Am Acad Dermatol. 1996 Apr;34(4):667-72.

88 Gean CJ, Tur E, Maibach HI, Guy RH. Cutaneous responses to topical methyl nicotinate in black, oriental, and Caucasian subjects. Arch Dermatol Res. 1989 Apr;281(2):95-8.

89 Luther N, Darvin ME, Sterry W, Lademann J, Patzelt A. Ethnic differences in skin physiology, hair follicle morphology and follicular penetration. Skin Pharmacol Physiol. 2012; 25(4):182-91.

90 Frosch PJ, Kligman AM. The chamber-scarification test for irritancy. Contact Dermatitis. 1976 Dec;2(6):314-24.

91 Marshall. New skin diseases in Africa. 1970. Available from: https://repository.up.ac.za/ bitstream/handle/2263/39731/Marshall New(1970).pdf?sequence $=1$.

92 Clark. Skin assessment in dark pigmented skin: a challenge in pressure ulcer prevention. 2010. Available from: https://europepmc.org/ article/med/20836475.

93 Robinson MK. Population differences in acute skin irritation responses. Race, sex, age, sensitive skin and repeat subject comparisons. Contact Dermatitis. 2002 Feb;46(2):86-93.

94 Pinnagoda J, Tupkek RA, Agner T, Serup J. Guidelines for transepidermal water loss (TEWL) measurement. Contact Dermatitis. 1990 Mar;22(3):164-78.

95 Jourdain $\mathrm{R}$, de Lacharrière $\mathrm{O}$, Bastien $\mathrm{P}$, Maibach HI. Ethnic variations in self-perceived sensitive skin: epidemiological survey. Contact Dermatitis. 2002 Mar;46(3):162-9.

96 Jothishankar B, Stein SL. Impact of skin color and ethnicity. Clin Dermatol. 2019 Sep;37(5): 418-29.
Influence of Ethnicities and Skin Color Variations in Different Populations
Skin Pharmacol Physiol 2022;35:65-76 DOI: $10.1159 / 000518826$ 
97 Davis SA, Narahari S, Feldman SR, Huang W, Pichardo-Geisinger RO, McMichael AJ. Top dermatologic conditions in patients of color: an analysis of nationally representative data. J Drugs Dermatol. 2012 Apr;11(4): 466-73.

98 Chung CL, Nadhan KS, Shaver CM, Ogrich LM, Abdelmalek M, Cusack CA, et al. Comparison of posttransplant dermatologic diseases by race. JAMA Dermatol. 2017 Jun; 153(6):552.

99 Ketchum LD. Hypertrophic scars and keloids. Clin Plast Surg. 1977;4(2):301-10.

100 Alhady SM, Sivanantharajah K. Keloids in various races. A review of 175 cases. Plast Reconstr Surg. 1969;44(6):564-6.

101 Deleo VA, Alexis A, Warshaw EM, Sasseville D, Maibach HI, DeKoven J, et al. The association of race/ethnicity and patch test results: North American Contact Dermatitis Group, 19982006. Dermatitis. 2016 Sep;27(5):288-92.

102 Blomberg M, Rifas-Shiman S, Camargo CJ Jr, Gold D, Thyssen J, Litonjua A, et al. Differences in incidence and persistence of atopic dermatitis by race/ethnicity. Dermatol Online J. 2016;22(9). Available from: https://escholarship.org/uc/item/7zx5j55x. http://dx.doi. org/10.5070/d3229032537.

103 Bhattacharya T, Silverberg JI. Efficacy of systemic treatments for atopic dermatitis in racial and ethnic minorities in the United States. JAMA Dermatol. 2014;150(11): 1232-4.

104 Norton HL, Kittles RA, Parra E, McKeigue $\mathrm{P}$, Mao X, Cheng K, et al. Genetic evidence for the convergent evolution of light skin in Europeans and East Asians. Mol Biol Evol. 2006 Dec;24(3):710-22.

105 Ginger RS, Askew SE, Ogborne RM, Wilson S, Ferdinando D, Dadd T, et al. SLC24A5 encodes a trans-golgi network protein with potassium-dependent sodium-calcium exchange activity that regulates human epidermal melanogenesis. J Biol Chem. 2008 Feb; 283(9):5486-95.

106 Lamason RL, Mohideen MA, Mest JR, Wong AC, Norton HL, Aros MC, et al. SLC24A5, a putative cation exchanger, affects pigmentation in zebrafish and humans. Science. 2005 Dec;310(5755):1782-6.

107 Vogel P, Read RW, Vance RB, Platt KA, Troughton K, Rice DS. Ocular albinism and hypopigmentation defects in Slc24a5-/mice. Vet Pathol. 2008 Mar;45(2):264-79.

108 Soejima M, Koda Y. Population differences of two coding SNPs in pigmentation-related genes SLC24A5 and SLC45A2. Int J Legal Med. 2006 Dec;121(1):36-9.

109 Canfield VA, Berg A, Peckins S, Wentzel SM, Ang KC, Oppenheimer S, et al. Molecular phylogeography of a human autosomal skin color locus under natural selection. G3. 2013 Nov;3(11):2059-67.

110 Mariat D, Taourit S, Guérin G. A mutation in the MATP gene causes the cream coat colour in the horse. Genet Sel Evol. 2003 Jan; 35(1):119-33.
111 Fukamachi S, Shimada A, Shima A. Mutations in the gene encoding $\mathrm{B}$, a novel transporter protein, reduce melanin content in medaka. Nat Genet. 2001 Aug;28(4):381-5.

112 Gunnarsson U, Hellström AR, Tixier-Boichard M, Minvielle F, Bed'hom B, Ito S, et al. Mutations in SLC45A2 cause plumage color variation in chicken and Japanese quail. Genetics. $2007 \mathrm{Feb}$;175(2):867-77.

113 Martínez-Cadenas C, López S, Ribas G, Flores C, García O, Sevilla A, et al. Simultaneous purifying selection on the ancestral MC1R allele and positive selection on the melanoma-risk allele V60L in South Europeans. Mol Biol Evol. 2013 Dec;30(12): 2654-65.

114 Rees JL, Flanagan N. Pigmentation, melanocortins and red hair. QJM. 1999 Mar;92(3): 125-31.

115 Marklund L, Moller MJ, Sandberg K, Andersson L. A missense mutation in the gene for melanocyte-stimulating hormone receptor (MCIR) is associated with the chestnut coat color in horses. Mamm Genome. 1996 Dec; 7(12):895-9.

116 Takeuchi S, Suzuki H, Yabuuchi M, Takahashi S. A possible involvement of melanocortin 1-receptor in regulating feather color pigmentation in the chicken. Biochim Biophys Acta. 1996 Aug;1308(2):164-8.

117 Sturm RA. GSTP1 and MC1R in melanoma susceptibility. Br J Dermatol. 2012 Jun; 166(6):1155-6.

118 Tiosano D, Audi L, Climer S, Zhang W, Templeton AR, Fernández-Cancio M, et al. Latitudinal clines of the human vitamin D receptor and skin color genes. G3. 2016;6(5): 1251-66.

119 Nan H, Kraft P, Hunter DJ, Han J. Genetic variants in pigmentation genes, pigmentary phenotypes, and risk of skin cancer in Caucasians. Int J Cancer. 2009 Aug;125(4):90917.

120 Valenzuela RK, Ito S, Wakamatsu K. Prediction model validation: normal human pigmentation variation. J Forensic Res. 2011;2: 8.

121 Sturm RA, Duffy DL. Human pigmentation genes under environmental selection. Genome Biol. 2012;13(9):248.

122 Yuasa I, Umetsu K, Harihara S, Kido A, Miyoshi A, Saitou N, et al. Distribution of two Asian-related coding SNPs in the MC1R and OCA2 genes. Biochem Genet. 2007 Aug; 45(7-8):535-42.

123 Hider JL, Gittelman RM, Shah T, Edwards M, Rosenbloom A, Akey JM, et al. Exploring signatures of positive selection in pigmentation candidate genes in populations of East Asian ancestry. BMC Evol Biol. 2013;13(1):150.

124 Hoyle DJ, Rodriguez-Fernandez IA, Dell'angelica EC. Functional interactions between OCA2 and the protein complexes BLOC-1, BLOC-2, and AP-3 inferred from epistatic analyses of mouse coat pigmentation. Pigment Cell Melanoma Res. 2011 Apr;24(2):275-81.
125 Edwards M, Bigham A, Tan J, Li S, Gozdzik A, Ross $\mathrm{K}$, et al. Association of the OCA2 polymorphism His615Arg with melanin content in east Asian populations: further evidence of convergent evolution of skin pigmentation. PLoS Genet. 2010 Mar;6(3): e1000867.

126 Abe Y, Tamiya G, Nakamura T, Hozumi Y, Suzuki T. Association of melanogenesis genes with skin color variation among Japanese females. J Dermatol Sci. 2013 Feb; 69(2):167-72.

127 Alonso S, Izagirre N, Smith-Zubiaga I, Gardeazabal J, Díaz-Ramón JL, Díaz-Pérez $\mathrm{JL}$, et al. Complex signatures of selection for the melanogenic loci TYR, TYRP1 and DCT in humans. BMC Evol Biol. 2008; $8(1): 74$.

128 Jin W. Admixture dynamics, natural selection and diseases in admixed populations. Netherlands: Springer; 2015. Available from: https://books.google.co.in/books? id $=5$ AmkCgAAQBAJ.

129 Deng L, Ruiz-Linares A, Xu S, Wang S. Ancestry variation and footprints of natural selection along the genome in Latin American populations. Sci Rep. 2016 Feb;6(1):21766.

130 Beleza S, Johnson NA, Candille SI, Absher DM, Coram MA, Lopes J, et al. Genetic architecture of skin and eye color in an African-European admixed population. PLoS Genet. 2013 Mar;9(3):e1003372.

131 Wang S, Ray N, Rojas W, Parra MV, Bedoya G, Gallo C, et al. Geographic patterns of genome admixture in Latin American Mestizos. PLoS Genet. 2008 Mar;4(3):e1000037.

132 Bonilla C, Shriver MD, Parra EJ, Jones A, Fernández JR. Ancestral proportions and their association with skin pigmentation and bone mineral density in Puerto Rican women from New York city. Hum Genet. 2004 Jun;115(1): 57-68.

133 Shriver MD, Parra EJ, Dios S, Bonilla C, Norton H, Jovel C, et al. Skin pigmentation, biogeographical ancestry and admixture mapping. Hum Genet. 2003 Apr;112(4): 387-99.

134 Zeigler-Johnson C, Panossian S, Gueye SM, Jalloh M, Ofori-Adjei D, Kanetsky PA. Population differences in the frequency of the agouti signaling protein g.8818A $>\mathrm{G}$ polymorphism. Pigment Cell Res. 2004 Apr; 17(2):185-7.

135 Markiewicz E, Idowu OC. Melanogenic difference consideration in ethnic skin type: a balance approach between skin brightening applications and beneficial sun exposure. Clin Cosmet Investig Dermatol. 2020 Mar;13:215-32.

136 Pillaiyar T, Namasivayam V, Manickam M, Jung SH. Inhibitors of melanogenesis: an updated review. J Med Chem. 2018 Sep; 61(17):7395-418.

137 Zhu PY, Yin WH, Wang MR, Dang YY, Ye $\mathrm{XY}$. Andrographolide suppresses melanin synthesis through Akt/GSK3 $\beta / \beta$-catenin signal pathway. J Dermatol Sci. 2015 Jul; 79(1):74-83. 